\title{
The Main Hazard Characteristics and Safety Management Measures of Flammable Solids
}

\author{
Zhengyang $\mathrm{An}^{1, \mathrm{a}}$ \\ ${ }^{1}$ Kunming Fire Service Training School \\ a112357772@qq.com
}

Keywords: Flammable solids; Hazard characteristics; Safety management

\begin{abstract}
Due to the sensibility to heat, impact and friction, and being vulnerable to external fire ignited, flammable solids have high burning speed and may produce toxic combustion products. Based on the analysis of the main hazard characteristics and influencing factors of flammable solids, the safety management measures were presented. nitro-compounds.
\end{abstract}

\section{Introduction}

Generally, flammable solids have low ignition point, high combustion speed, whilst their corresponding combustion products also have certain toxicity. Therefore, heavy casualties and huge property losses, as well as serious environmental pollution, can occur once flammable solids catch fire.

\section{Concept and Classification of Flammable Solids}

Concept of Flammable Solids. Flammable solids refer to solids with low ignition point, sensitivity to heat, impact and friction, which are easily ignited by external fire, burn rapidly and emit toxic gas. Flammable solids usually include easy combustion solids, solids catching fire by friction, self decomposition reactive solids discharging heat intensely even in the absence of oxygen (air), solid desensitized explosives which are formed by wetting with water, alcohol or other substances to dilute explosive material.

Classification of Flammable Solids. According to ignition point, combustion speed and toxicity, flammable solids can be divided into Grades I and II.

Grade I Flammable Solids. Substances of Grade I have low ignition point, fast combustion speed, and itself or combustion products are usually toxic, such as red phosphorus and phosphorous compounds (three sulfide phosphorus, etc.), nitro-compounds (dinitrotoluene, dinitro naphthalene, 3,7-dinitroso-1,3,5,7-tetraazobicyclo-nonane), nitrocellulose (nitrogen content $<12.5 \%$ ), desensitive flash powder and so on.

Grade II Flammable Solids. Compared to Grade I flammable solids, this kind of materials have weaker combustion performance, slower burning speed, and itself or combustion products have less toxicity, such as celluloid, magnesium, aluminum, naphthalene, sulfur, raw rosin, etc..

During the production, storage and use, Grade I flammable solids are designated as A fire hazard, whilst Grade II are designated as B fire hazard. Due to their variety and quantity used in the production and daily life, common flammable solids with ignition point above $300{ }^{\circ} \mathrm{C}$, such as natural fibers of cotton, linen, wood and straw, synthetic fibers and products of nylon, polyester and acrylic, synthetic resin and products of polyethylene, polypropylene and PVC, grains and their products of wheat and soybeans, rubber and products of natural rubber and synthetic rubber, will cause serious losses in fire, thus the safety management should be carried out according to $\mathrm{C}$ fire hazard

\section{Main Hazard Characteristics of Flammable Solids}

Low Ignition Point and Easy to Ignite. The ignition points of flammable solids are relatively low, generally below $300{ }^{\circ} \mathrm{C}$, and flammable solids can be ignited at room temperature by the effect of ignition source with very little energy. For example, powder of magnesium or aluminium can be ignited 
by $20 \mathrm{~mJ}$ ignition energy, whilst that of sulfur or the raw rosin is only $15 \mathrm{~mJ}$. Furthermore, some flammable solids can also cause combustion when subjected to external forces such as friction and impact. Therefore, it should be paid attention to handle gently, avoid external forces such as friction and impact in processes of storage, transportation, loading and unloading of flammable solids should.

Flammability and Explosivity in Contact with Acid and Oxidant. The vast majority of flammable solids in contact with corrosive substance of inorganic acids or oxidizing substances etc., can immediately cause a fire or explosion. The reaction of naphthalene with fuming sulfuric acid is so strong to cause an explosion. Whilst that of red phosphorus with potassium chlorate and that of sulfur with sodium or potassium chlorate, will induce fire or explosion by slight friction or collision. Therefore, mixed storage or mixed transportation of flammable solids with oxidants or acids is absolutely forbidden.

Flammability in Contact with Water. Sulfur phosphides have the flammability not only in case of fire or heating, but also in case of contact with water. For example, phosphorus pentasulfide and phosphorus sesquisulphide can produce flammable, corrosive and toxic gas of hydrogen sulfide when contacting with water. Therefore, attention should be paid to waterproof, moisture-proof of such substances. Moreover, water based extinguish agent is forbidden to fight fire in these cases

Hazards of Spontaneous Combustion. Flammable solids of celluloid, nitrocellulose and their products are easy to spontaneous combustion by accumulated and not scattered heat. Therefore, in the storage and long-distance water transportation of this kind of flammable solid, the ventilation, cooling and moisture proof must be noted, and the stacking should be neither large nor high. Moreover, the management should be strengthened to prevent fire caused by spontaneous combustion.

Toxicity of Itself or Combustion Product. A lot of flammable solids or gases produced after combustion are toxic. For example, in case of sulfur and phosphorus sesquisulfide etc., not only contact with the skin (especially in case of summer sweating ) but also dust inhalation can cause poisoning. As for flammable solids of nitro compound, nitrocellulose and its products, and diazoaminobenzene, a fire may turn into an explosion in rapid combustion conditionsbecause of unstable groups of nitro $\left(-\mathrm{NO}_{2}\right)$, nitroso (-NO) and nitrogen (-N=N-,. Whilst combustion will produce a large number of toxic gases including $\mathrm{CO}, \mathrm{HCN}$ and nitrogen oxide compounds. So special attention should be paid to the poisoning prevention.

\section{Influencing Factors on the Hazards of Flammable Solids}

Except for chemical composition and molecular structure, the factors influencing on the hazards of flammable solids are as follows:

Specific Surface Area. For the same solid material, the greater is the specific surface area (the surface area per unit volume), the more is the hazard of fire, whilst the smaller on the contrary. The reason is that the burning of solid usually starts from the surface of the material, and then gradually moves into the material, so the larger material surface area is, and the contact area with oxygen in the air is larger, and so the easier is the oxidation and the quicker is the burning. As for a piece of wood $1 \mathrm{~cm} 3$, the surface area will increase from the original $6 \mathrm{~cm} 2$ to $6000 \mathrm{~cm} 2$ after being divided into $0.01 \mathrm{~mm}$ square particles. Therefore, due to the increased contact area with oxygen in the air, the powder is more flammable than the block, and the loose material is more flammable than the stack,. For example, the ignition point of pine wood is $238 \mathrm{oC}$, while that of pine powder is $96^{\circ} \mathrm{C}$.

Thermal Decomposition Temperature. Some flammable solids, such as nitrocellulose and its products, nitro compounds, ammonium nitrate, certain synthetic resins and cotton and other flammable solid substances, do not melt after heating, but the decomposition phenomenon happen. Therefore, the fire risk depends on the decomposition temperature. The general rule is that the lower is the thermal decomposition temperature, the faster is the burning speed and the greater is the fire risk. The relationship between the thermal decomposition temperature and ignition point of some flammable solids are listed in Table 1.

In general, the principle of nitro-compounds disposal is as follows: Wear air respirators or gas masks, do not smoke near the leaking area, and eliminate all open flames, sparks or flames, do not contact nor 
across the spillage. Plug the leak or flip the leaked container to prevent leaking in the premise of security. Spray water to suppress steam or to change the direction of the vapor cloud. It is prohibited to rinse the spillage or leakage directly with water. Prevent the steam of spillage from passing through the sewer, ventilation system and the airtight space to the leakage isolation area until the gas is scattered. For the disposal of spillage, dust should be avoided, and collected in a dry, clean, covered containers with a clean shovel, can also be covered with plastic cloth, canvas, and then collected or transported to the professional disposal places handling dangerous chemicals.

Disposal Measures against Explosion Accidents. In the production process, especially in the distillation process, nitro-compounds are heated in a closed device, while the decomposition of nitro-compounds is exothermic reaction with gas products, in addition, the thermal decomposition has self-catalytic properties. Hence, the decomposition rate will be faster and faster. Therefore, the danger of the explosion is great. In the event of an accident during the transport process, nitro-compounds may form toxic and flammable vapors, and both sparks and pyrotechnics should be eliminated for the first time at the site to prevent the release of the vapor from causing the explosion [11]. Explosion caused by the fire should be extinguished with dry powder, carbon dioxide, mist water, anti-soluble foam. Exposed parts or sites endangering the safety of human body should be provided with protective cover, safety barrier baffle to prevent unrelated personnel approaching. It is necessary to build dike or dig holes to collect spillage and waste water.

Table 1 The relationship between the thermal decomposition temperature and ignition point of some flammable solids

\begin{tabular}{|c|c|c|}
\hline Solids & $\begin{array}{c}\text { Thermal decomposition } \\
\text { temperature }\left({ }^{\circ} \mathrm{C}\right)\end{array}$ & Ignition point $\left({ }^{\circ} \mathrm{C}\right)$ \\
\hline Nitrocellulose & 40 & 180 \\
\hline Celluloid & $90 \sim 100$ & $150 \sim 180$ \\
\hline Hemp & 107 & $150 \sim 200$ \\
\hline Cotton & 120 & 200 \\
\hline Silk & 235 & $250 \sim 300$ \\
\hline
\end{tabular}

Water Content. The combustion performance of solid is different with different water content. Such as nitrocellulose with water content above $35 \%$ is relatively stable, and there is a little fire hazard in case of water content $20 \%$, since slight friction or impact can easily cause fire. Also, in the management of hazardous chemicals, dry or wet dinitrophenol is managed as explosive for its great explosivity, but when the water content is more than $15 \%$, dinitrophenol is mainly treated as flammable solid for its flammability. When completely dissolved in water, the combustion performance of dinitrophenol can be greatly reduced, and the main performance is its toxicity. Hence, dinitrophenol in this case can be listed in toxic substances management.

\section{Safety Management of Flammable Solids}

he relationship between safety and danger is the unity of opposites, like the positive and negative aspects of a coin, which not only are mutually existing conditions, but also can mutually transform, existing in a state of unity of opposites.

The traditional security work often treats the safety and danger absolutely and incompatibly, and pursuits absolute security from its good subjective intentions. Once a potential risk induces an accident, it will be treated as absolute insecure, which is neither scientific nor realistic. Because of the complexity and variability of things (especially the interaction of risk factors), as well as the limitations of human knowledge, it is impossible to eliminate all danger or accidents at all time and in all space. However, it is possible to avoid accidents, especially serious personal injury accident, in a certain period of time of a specific work. 
(1) Store in a cool and ventilated warehouse, away from fire, heat, oxidants and acids (especially oxidizing acids). Do not mix with other hazardous chemicals.

(2) Handle lightly during loading and unloading, prevent from dragging, pulling, throwing and hitting, and keep the packaging intact.

(3) Pay attention to ventilation and heat, prevent damp moldy, and pay attention to shelf life when store nitrocellulose and its products.

(4) Always check the packaging of nitrocellulose containing water or ethanol as stabilizer, repair the damage promptly, regularly check of the stabilizer, and if necessary, add stabilizer to keep wetting uniformly.

(5) Treat various accidents differently in the storage. If red phosphorus smokes, the smoking red phosphorus should be moved out of the warehouse immediately and put out with sand, dry powder and other extinguishing agents, whilst water should be applied for bulk sulfur, and only sand and dry powder can be used to extinguish the combustion of metal powder, such as magnesium, aluminum and so on, in case of which water, acid-base extinguishing agent, foam extinguishing agent and carbon dioxide extinguishing agent are forbidden.

\section{References}

[1] Fire Department of the Ministry of public security. Special service training[M]. Shanghai: Wenhui Press, 2001, March

[2] Chen Jiaqiang. Discussion on rescue of chemical disaster accident[Z], Chinese Fire, 1998(4-5)

[3] He Liqiu. Fire combustion science[M]. Yunnan: Yunnan People's Publishing House, 2006, May

[4] Zhang Guanghua. Safety technology and management of hazardous chemicals production[M]. Beijing: China Petrochemical Press, 2004

[5] Yang Lihong. Measures and Countermeasures to strengthen the management of pesticide [J]. Pesticide science and management, 2012, 33(4): 7 9

[6] Chen Meibao, Wang Wenhe. Basic knowledge of hazardous chemical safety. Beijing. China Labour \& Social Security Publishing House, 2010

[7] Fire Department of the Ministry of public security of the people's Republic of China. China Fire Manual: The seventh volume of hazardous chemicals, special agents and dust[M]. Shanghai: Shanghai Science and Technology Press, 2006.

[8] Tang Chaogang. Fundamental safety management of hazardous chemicals[M]. Beijing: China Machine Press, 2014

[9] Zhao Qingxian, Shao Hui, Ge Xiukun. Safety management of hazardous chemicals[M]. Beijing. China Petrochemical Press, 2010

[10] Su Hualong. Safety management of hazardous chemicals[M]. Beijing. Chemical Industry Press, 2006 